\title{
ESTUDOS DE EQUILÍBRIO NA SORÇÃO DE Cr(III) POR GRANULADOS BIOCLÁSTICOS
}

\author{
D. M. VENEU ${ }^{\prime *}$, L. YOKOYAMA', O. G. C. CUNHA', C. L. SCHNEIDER ${ }^{2}$ e M. B. M. MONTE ${ }^{2}$ \\ ${ }^{1}$ Universidade Federal do Rio de Janeiro - UFRJ \\ ${ }^{2}$ Centro de Tecnologia Mineral - CETEM \\ diegomveneu@yahoo.com.br*
}

Artigo submetido em setembro/2016 e aceito em outubro/2016

DOI: $10.15628 /$ holos.2016.5098

\section{RESUMO}

Os Granulados Bioclásticos provenientes de algas calcárias Lithothamnium calcareum são uma fonte mineral marinha e a sua utilização pode não ser recente, porém ainda necessita de diversas pesquisas para avaliar os seus verdadeiros potenciais e níveis de utilização em diferentes segmentos. Este estudo avalia a aplicação deste material para tratamento de soluções aquosas contendo íons $\mathrm{Cr}$ (III) através do processo de sorção. Os resultados de remoção e captação mais significativos de íons $\mathrm{Cr}$ (III) foram obtidos na faixa de $\mathrm{pH}$ entre 4 a 8 , correspondendo a $99,9 \%$ e $12,4 \mathrm{mg} \mathrm{g}^{-1}$, respectivamente.
Nas concentrações iniciais de 5 a 200 mg. ${ }^{-1}$ foram alcançadas remoções $\geq 97,9 \%$. Para a captação, o valor mais elevado foi obtido na concentração de $350 \mathrm{mg} . \mathrm{L}^{-1}$, correspondendo a $161 \mathrm{mg} \cdot \mathrm{g}^{-1}$. Os modelos de Langmuir, Dubinin-Radushkevich e Temkin ajustaram-se aos dados de sorção apresentando valores de $R^{2}$ de 0,953, 0,942 e 0,959 , respectivamente. Os valores de $q_{\max }$ obtidos do modelo de Langmuir e de Dubinin-Radushkevich foram de 178,57 mg.g ${ }^{-1}$ e $171,19 \mathrm{mg} \cdot \mathrm{g}^{-1}$, respectivamente. Os resultados de MEV/EDX mostram precipitados com composição elementar de $\mathrm{C}$, $\mathrm{O}$ e $\mathrm{Cr}$.

PALAVRAS-CHAVE: Tratamento de efluentes, sorção, cromo, alga calcária.

\section{SORPTION EQUILIBRIUM STUDIES OF Cr(III) BY BIOCLASTIC GRANULES}

\begin{abstract}
Bioclastic Granules from calcareous alga Lithothamnium calcareum are a marine mineral source and its use can not be recent, but still needs several researches to evaluate their true potential and utilization levels in different segments. This study assesses the application of this material for the treatment of aqueous solutions containing $\mathrm{Cr}(\mathrm{III})$ ions through the sorption process. The most significant results of removal and uptake for $\mathrm{Cr}(\mathrm{III})$ ions were obtained in a range of $\mathrm{pH}$ between 4 to 8 , corresponding to $99,9 \%$ and $12,4 \mathrm{mg}^{-1} \mathrm{~g}^{-1}$, respectively. At
\end{abstract}

the initial concentrations of from 5 to $200 \mathrm{mg} \cdot \mathrm{L}^{-1}$ removal $\geq 97.9 \%$ were achieved. For the uptake, the higher value obtained was at concentration of $350 \mathrm{mg} . \mathrm{L}^{-1}$, corresponding to $161 \mathrm{mg} \cdot \mathrm{g}^{-1}$. The Langmuir, DubininRadushkevich and Temkin adjusted to sorption data showing $R^{2}$ values of $0.953,0.942$ and 0.959 , respectively. The $q_{\max }$ values obtained from the Langmuir and DubininRadushkevich model were $178.57 \mathrm{mg}^{-g^{-1}}$ and 171.19 mg. $\mathrm{g}^{-1}$, respectively. The results of SEM/EDX showed precipitated with elemental composition of $\mathrm{C}, \mathrm{O}$ and $\mathrm{Cr}$.

KEYWORDS: Wastewater treatment, sorption, chrome, calcareous algae. 


\section{INTRODUÇÃO}

O termo metal pesado é definido como sendo todo metal que possui densidade específica maior igual a $5 \mathrm{g.cm}-3$ (ROSTAMIAN et al., 2011). Segundo WANG e CHEN (2006), os metais pesados podem ser divididos em três classes, metais tóxicos ( $\mathrm{Hg}, \mathrm{Cr}, \mathrm{Pb}, \mathrm{Zn}, \mathrm{Cu}, \mathrm{Ni}, \mathrm{Cd}, \mathrm{As}, \mathrm{Co}$, Sn, etc), radionuclídeos ( $\mathrm{U}, \mathrm{Th}, \mathrm{Ra}, \mathrm{Am}$, etc) e metais preciosos ( $\mathrm{Pd}, \mathrm{Pt}, \mathrm{Ag}, \mathrm{Au}, \mathrm{Ru}$, etc). A contaminação por metais pesados é ainda hoje um problema ambiental em países desenvolvidos e em desenvolvimento em todo o mundo (DAN'AZUM e BICHI, 2010; MOMODU e ANYAKORA, 2010). Com a rápida industrialização e o desenvolvimento econômico, os metais pesados continuam a ser introduzidos no ambiente através de fontes pontuais e difusas (IBRAHIM et al., 2010).

As formas de cromo tri e hexavalente são mais estáveis e aparecem na composição de óxidos, sulfatos, cromatos, dicromatos e sais básicos. A forma metálica não é encontrada livre na natureza, mas obtida após o processamento industrial do minério de cromo (CETESB, 2012). As principais fontes de cromo para o ambiente são as indústrias de metalurgia, galvanoplastia, fabricação de baterias, agroquímicos, aço básico, celulose e papel, petroquímica, curtumes e fertilizantes (EL-SHERIF et al., 2013). Apesar do $\mathrm{Cr}$ (III) ser cerca de 300 vezes menos tóxico do que a o $\mathrm{Cr}(\mathrm{VI})$, esta forma, pode causar perturbações estruturais nas membranas eritrocitárias (SUWALSKY et al., 2008).

O tratamento convencional de efluentes contendo metais envolve processos químicos e físicos, incluindo precipitação química, adsorção, processo de membrana, troca iônica, flotação, dentre outros (SELATNIA et al., 2004). A aplicação de alguns destes processos resulta em custos elevados, como por exemplo os processos de membrana e troca iônica, ou podem produzir resíduos de difícil tratamento, como a oxidação e precipitação química (ZOBOULIS et al., 2004). Outros simplesmente empregam agentes químicos que podem contribuir para a transformação de um poluente em outro, como acontece na flotação quando se empregam aminas como agentes coletores (TOREM e CASQUEIRA, 2003). Esses processos são geralmente incapazes de reduzir as concentrações dos metais para valores entre 0,1 e $3 \mathrm{mg} \cdot \mathrm{L}^{-1}$, não satisfazendo os limites de lançamento determinados pelas normas e legislações pertinentes (SANCHEZ e AYUSO, 2002).

Face a essa problemática ambiental, é crescente a necessidade de métodos econômicos e eficientes para a remoção de metais, resultando no desenvolvimento de novos materiais e tecnologias de tratamento. Alga marinha calcária é um termo genérico que designa várias espécies de algas vermelhas calcificadas, nas quais ocorre um pigmento rosa avermelhado fotossinteticamente ativo na forma viva do organismo (LEE, 1999). A partir do depósito de sais inorgânicos, a alga morre e perde a coloração avermelhada característica da película viva superficial da crosta algálica, desenvolvendo um esqueleto rico em carbonato de cálcio e magnésio precipitado em suas paredes celulares, sob a forma de cristais de calcita conferindo a alga uma coloração branca-amarelada (DIAS, 2000). Esta alga calcárea é muitas vezes denominada como calcário biogênico ou biodentrítico marinho e/ou granulado bioclástico.

O presente estudo avalia a capacidade e eficiência dos Granulados Bioclásticos (GB) provenientes da alga calcária Lithothamnium calcareum como um material sorvente para o tratamento de soluções aquosas contendo $\mathrm{Cr}(\mathrm{III})$ através de ensaios em batelada. 


\section{MATERIAIS E MÉTODOS}

\subsection{Material e reagente}

Os Granulados Bioclásticos foram fornecidos pela empresa Algarea Mineração S.A. que realiza a extração pontualmente na jazida localizada no Espírito Santo a aproximadamente $24 \mathrm{~km}$ do litoral de Itapemirim a uma profundidade de 13 a $20 \mathrm{~m}$. O material extraído se trata do sedimento mineralizado da alga morta. O processo de beneficiamento é constituído pelas etapas de secagem, moagem, classificação (ciclones), ensacamento e estocagem do minério. As soluções metálicas utilizadas nos ensaios foram preparadas com água deionizada a partir do sal de $\mathrm{CrCl}_{3} .6 \mathrm{H}_{2} \mathrm{O}(98 \%)$ fornecido pela Vetec.

\subsection{Experimentos de sorção}

Os fatores que afetam a taxa de sorção e a capacidade de captação dos Granulados Bioclásticos foram estudados em escala de bancada. Todos os ensaios foram realizados em frascos erlenmeyer de $500 \mathrm{~mL}$, empregando um volume de solução metálica de $100 \mathrm{~mL}$, velocidade de rotação de $250 \mathrm{rpm}$ em uma plataforma de rotação horizontal (Cientec CT-712). Para elucidar as condições ótimas para o processo de sorção, foram escolhidas as variáveis $\mathrm{pH}(2$ a 8 ) e concentração inicial de metal (5 a $400 \mathrm{mg} \cdot \mathrm{L}^{-1}$ ).

Após cada ensaio realizado, as partículas de Granulados Bioclásticos contendo os íons $\mathrm{Cr}$ (III) foram concentradas por meio de filtração em uma membrana de $0,22 \mu \mathrm{m}$, sendo posteriormente removidas para que o permeado (solução metálica remanescente) fosse coletado e transformado em amostra, sendo estas acidificadas com uma solução de $\mathrm{HCl}(0,1 \mathrm{M})$ para sua preservação e posterior análise da concentração residual do íon metálico por análise elementar em ICP/OES em um equipamento Perkin Elmer Optima 4300DV. A remoção e a capacidade de sorção são calculadas mediante as Equações (1) e (2), respectivamente.

$$
\begin{gathered}
R=\frac{\left(C_{i}-C_{e q}\right)}{C_{i}} \cdot 100 \\
q=\frac{V\left(C_{i}-C_{e q}\right)}{M}
\end{gathered}
$$

Onde: R é a remoção de íons $\mathrm{Cr}$ (III) (\%); q é a capacidade de captação dos íons $\mathrm{Cr}$ (III) (mg.g$\left.{ }^{1}\right)$; $C_{i}$ é a concentração inicial dos íons $\operatorname{Cr}(I I I)\left(\mathrm{mg}^{-\mathrm{L}^{-1}}\right)$; $\mathrm{C}_{\text {eq }}$ é a concentração dos íons $\mathrm{Cr}(\mathrm{III})$ no equilíbrio ( $\left.\mathrm{mg} . \mathrm{L}^{-1}\right)$; $V$ é o volume da solução contendo os íons $\mathrm{Cr}(\mathrm{III})$ (L); $\mathrm{M}$ é a massa do sorvente (g).

\subsection{Isotermas de Adsorção}

\subsubsection{Isoterma de Langmuir}

A isoterma de Langmuir foi inicialmente descrita para estudos de adsorção de gases em superfícies planas (LANGMUIR, 1918). Este modelo contém um número de suposições que são: (i) todos os sítios de ligação possuem uma afinidade igual para o soluto, (ii) a adsorção está limitada à formação de uma monocamada, e (iii) o número de espécies sorvidas não excede o número total 
de sítios na superfície, isto é, existe uma estequiometria de 1:1 entre os sítios de adsorção na superfície e o soluto (GADD, 2009). Basicamente, a equação da isoterma de Langmuir tem uma forma hiperbólica dada pela Equação (3):

$$
q=\frac{q_{\max } K_{a d s} C_{e q}}{1+K_{a d s} C_{e q}}
$$

Onde: q é a quantidade de soluto retido no sólido no equilíbrio $\left(\mathrm{mg} . \mathrm{g}^{-1}\right) ; \mathrm{q}_{\max }$ é o parâmetro de Langmuir relativo à capacidade de sorção $\left(\mathrm{mg} \cdot \mathrm{g}^{-1}\right)$; $\mathrm{K}_{\mathrm{ads}}$ é a constante de Langmuir relativa à energia de sorção (L.mg-1); $C_{\text {eq }}$ é a concentração do soluto na solução no equilíbrio (mg. $\left.\mathrm{L}^{-1}\right)$.

A Equação (3) pode ser linearizada, obtendo assim a Equação (4):

$$
\frac{C_{e q}}{q}=\frac{1}{q_{\max } K_{a d s}}+\frac{C_{e q}}{q_{\max }}
$$

Segundo FOO e HAMEED (2010), uma característica essencial da isoterma de Langmuir será expressa em termos de uma constante adimensional, conhecida como fator de separação " $\mathrm{L}_{\mathrm{L}}$ " expresso pela Equação (5):

$$
R_{L}=\frac{1}{1+K_{a d s} C_{o}}
$$

Onde: $R_{L}$ é o fator de separação; $K_{a d s}$ é a constante de Langmuir relativa à energia de adsorção (L. $\left.\mathrm{mg}^{-1}\right)$; $\mathrm{C}_{\mathrm{o}}$ é a concentração inicial do soluto na solução $\left(\mathrm{mg} . \mathrm{L}^{-1}\right)$.

Este fator indica a natureza do processo de sorção, para um valor de $R_{L}>1$ (desfavorável), para $R_{L}=1$ (linear), para $0<R_{L}<1$ (favorável) e $R_{L}=0$ (irreversível).

\subsubsection{Isoterma de Freundlich}

O modelo de isoterma de Freundlich é considerado apropriado para descrever tanto a sorção em multicamadas quanto a sorção em superfícies heterogêneas (HO et al., 2002). O modelo de Freundlich, Equação (6), não prevê a saturação da superfície baseada no processo de adsorção, correspondendo a uma distribuição exponencial de vários sítios de adsorção com energias diferentes, podendo assim ser aplicado a sistemas não ideais (FREUNDLICH, 1906).

$$
q=K_{f} C_{e q}{ }^{1 / n}
$$

Onde: q é a quantidade de soluto retido no sólido no equilíbrio $\left(\mathrm{mg} \cdot \mathrm{g}^{-1}\right)$; $\mathrm{C}_{\text {eq }}$ é a concentração do soluto na solução no equilíbrio $\left(\mathrm{mg} . \mathrm{L}^{-1}\right) ; \mathrm{K}_{\mathrm{f}}$ é a constante que indica a capacidade de adsorção (L. mg $\left.{ }^{-1}\right)$; n é a constante que indica a intensidade de adsorção.

A Equação (6) pode ser linearizada, obtendo assim a Equação (7):

$$
\log q=\log K_{f}+\frac{1}{n} \log C_{e q}
$$

\subsubsection{Isoterma de Dubinin-Radushkevich}

O modelo de Dubinin-Radushkevich (D-R) avalia a natureza de sorção, é mais geral do que a isoterma de Langmuir, já que esta não assume uma superfície homogênea ou um potencial de adsorção constante (FEBRIANTO et al., 2009). Dubinin em 1960 e Radushkevich em 1949 reportaram que a curva característica de adsorção está relacionada à estrutura porosa do 
sorvente. A Equação (8) representa a isoterma de Dubinin-Radushkevich e a Equação (9) representa o potencial de Polanyi.

$$
\begin{aligned}
& q=q_{\text {max }} \exp \left(-B \varepsilon^{2}\right) \\
& \varepsilon=R \operatorname{Rln}\left(1+1 / C_{e q}\right)
\end{aligned}
$$

Onde: q é a quantidade de soluto retido no sólido no equilíbrio $\left(\mathrm{mg} . \mathrm{g}^{-1}\right) ; \mathrm{q}_{\max }$ é a capacidade de adsorção máxima do sorvente $\left(\mathrm{mg}^{-\mathrm{g}^{-1}}\right) ; B$ é a constante relacionada à energia de sorção $\left(\mathrm{mol}^{2} \cdot \mathrm{kJ}^{-}\right.$ $\left.{ }^{2}\right)$; $\varepsilon$ é o potencial de Polanyi $\left(\mathrm{kJ} \cdot \mathrm{mol}^{-1}\right)$; R é a constante dos gases $\left(0,008314 \mathrm{~kJ} \cdot \mathrm{mol}^{-1} \cdot \mathrm{K}^{-1}\right)$; $\mathrm{T}$ é a temperatura absoluta (K); $C_{\text {eq }}$ é a concentração do soluto na solução no equilíbrio $\left(\mathrm{mg} \cdot \mathrm{L}^{-1}\right)$.

A Equação (8) pode ser linearizada, obtendo assim a Equação (10):

$$
\ln q=\ln q_{\max }-B \varepsilon^{2}
$$

Os valores da energia de sorção $\left(\mathrm{kJ} . \mathrm{mol}^{-1}\right)$ serão relacionados com a constante $B$ pelo uso da Equação (11). É definida como a variação de energia livre quando um mol de um íon será transferido do infinito, dentro da solução, para a superfície do sólido. Sendo esta energia relacionada com o fenômeno de adsorção que acontece no sistema sorvente/soluto (WANG et al., 2007). Se $E_{s}<8 \mathrm{~kJ} \mathrm{~mol}^{-1}$ a adsorção é de natureza física; Se $8 \mathrm{~kJ} \cdot \mathrm{mol}^{-1}<\mathrm{E}_{s}<16 \mathrm{~kJ} \cdot \mathrm{mol}^{-1} \mathrm{a}$ adsorção se da por troca iônica; Se $16 \mathrm{~kJ} . \mathrm{mol}^{-1}<\mathrm{E}_{\mathrm{s}}$ adsorção é de natureza química.

$$
E_{s}=1 / \sqrt{2 B}
$$

Onde: $E_{s}$ é a energia livre média de sorção $\left(\mathrm{kJ} \cdot \mathrm{mol}^{-1}\right)$.

Isoterma de Temkin

O modelo da equação de Temkin foi proposto para descrever a adsorção de hidrogênio em eletrodos de platina dentro de soluções ácidas (FEBRIANTO et al., 2009). Neste modelo, considerase o efeito das interações indiretas soluto/sorvente sobre as isotermas de adsorção assumindo que a queda no calor de adsorção é linear devido à cobertura da camada pelas interações soluto/sorvente e não logarítmica, como descrito na isoterma de Freundlich (BASHA et al., 2008). A Equação (12) representa a isoterma de Temkin:

$$
q=\frac{R T}{b} \ln \left(A C_{e q}\right)
$$

Onde: q é quantidade de soluto retido no sólido no equilíbrio $\left(\mathrm{mg} \cdot \mathrm{g}^{-1}\right) ; \mathrm{C}_{\mathrm{eq}}$ é a concentração do soluto na solução no equilíbrio ( $\left.\mathrm{mg} . \mathrm{L}^{-1}\right)$; T é a temperatura absoluta (K); R é a constante universal dos gases $\left(0,008314 \mathrm{~kJ} \cdot \mathrm{mol}^{-1} \cdot \mathrm{K}^{-1}\right)$; A é a constante da isoterma de Temkin (L. $\left.\mathrm{mg}^{-1}\right) ; \mathrm{b}$ é a constante relacionada ao calor de sorção $\left(\mathrm{kJ} \cdot \mathrm{mol}^{-1}\right)$.

A Equação (12) pode ser linearizada, obtendo assim a Equação (13):

$$
q=\frac{R T}{b} \ln A+\frac{R T}{b} \ln C_{e q}
$$

Microscopia Eletrônica de Varredura

As micrografias foram obtidas em um Microscópio Eletrônico de Varredura (MEV) FEI Quanta 400, equipado com Sistema de Energia Dispersa por espectrometria de raios X (EDS) Bruker Xflash 4030 para avaliar a morfologia dos Granulados Bioclásticos. A aquisição e tratamento dos dados gerados pelo EDS foram feitos por meio do software ESPRIT versão 9.1 da Brucker. As 
amostras foram secadas em uma estufa durante $24 \mathrm{~h}$ a uma temperatura de 60 ㅇ $\mathrm{C}$ e depositadas em fitas adesivas de carbono suportadas em discos metálicos onde finalmente sofreram recobrimento de uma película micrométrica de ouro a partir da evaporação em uma câmara metalizadora, possibilitando assim, a condução da corrente elétrica. As imagens das superfícies das amostras foram registradas em diversas magnitudes. A análise elementar por EDS foi realizada em diferentes pontos sobre a superfície, a fim de minimizar quaisquer anomalias possíveis resultantes da heterogeneidade da superfície analisada.

\section{RESULTADOS E DISCUSSÕES}

\subsection{Efeito do $\mathrm{pH}$}

Na Figura 1 pode-se observar o percentual de remoção e capatação dos íons $\mathrm{Cr}$ (III) na faixa de $\mathrm{pH}$ de 2,0 a 8,0. O percentual de remoção foi significativamente elevado em quase toda faixa de $\mathrm{pH}$ em estudo, a partir do $\mathrm{pH} 4$, a remoção foi praticamente total $(99,9 \%)$, correspondendo a concentrações residuais abaixo de $0,01 \mathrm{mg} \cdot \mathrm{L}^{-1}$. Os valores de remoção menos expressivos foram obtidos no pH 2 e 3, correspondendo aos valores de 96,2 e 98,3\%, respectivamente.As captações mantiveram-se também elevadas, apresentando um valor máximo correspondente a $12,4 \mathrm{mg}$ de $\mathrm{Cr}(\mathrm{III}) / \mathrm{g}$ de GB.

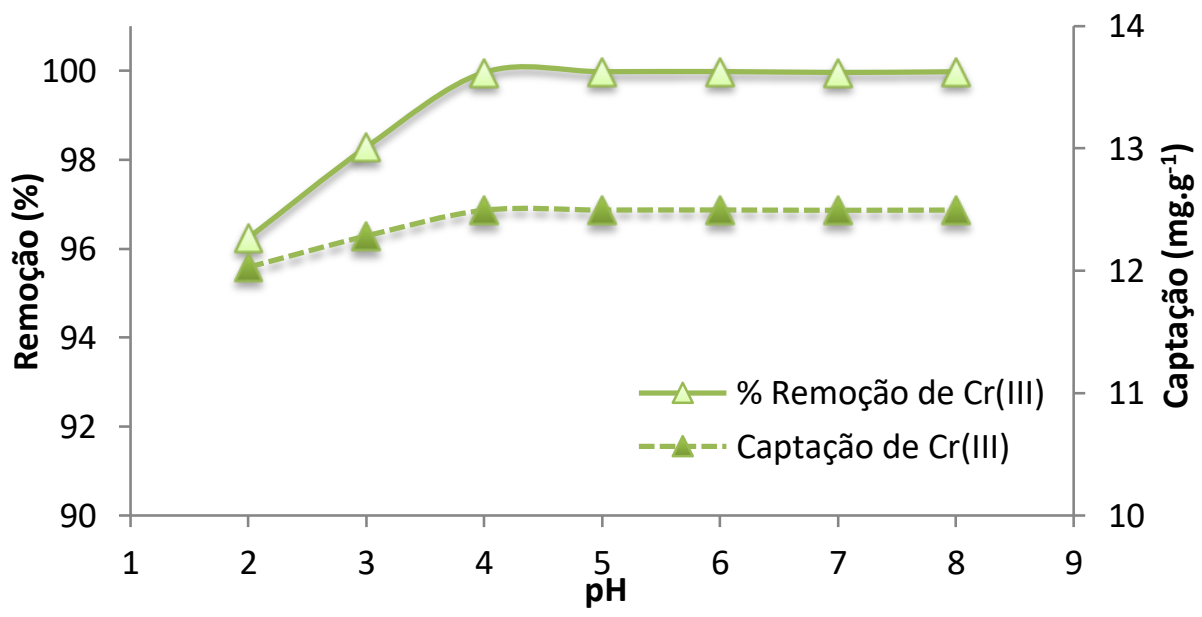

Figura 10: Efeito do pH na sorção de $\mathrm{Cr}$ (III) por GB (concentração inicial de metal: 25 mg. $\mathrm{L}^{-1}$; concentração do sorvente: $2 \mathrm{~g} . \mathrm{L}^{-1}$; tamanho de partícula: < $38 \mu \mathrm{m}$; temperatura: $25^{\circ} \mathrm{C}$; e tempo de contato: $240 \mathrm{~min}$ ).

Segundo a Resolução Conama 430 de 2011 que dispõe sobre condições, parâmetros, padrões e diretrizes para gestão do lançamento de efluentes em corpos de água receptores, as concentrações máximas permissíveis para lançamento de cromo trivalente e $1,0 \mathrm{mg} . \mathrm{L}^{-1}$ (BRASIL, 2011). De acordo com este valor, e comparando este aos obtidos após a sorção utilizando os GB, fica evidente que o processo é promissor e eficaz na redução das concentrações de $\mathrm{Cr}$ (III) para posterior lançamento em corpos receptores.

$\mathrm{O} \mathrm{pH}$ inicial das soluções metálicas utilizadas nos ensaios foram medidas e ajustadas para os diferentes valores de $\mathrm{pH}$, após a adição dos $\mathrm{GB}$, mais precisamente, no final dos ensaios, foram realizadas novas medições de $\mathrm{pH}$ onde verificou-se que em todos os ensaios, o pH final apresentou um valor aproximadamente de 7,2 independentemente do valor de $\mathrm{pH}$ inicial. Comportamento semelhante foi encontrado por SDIRI et al. (2012), que verificaram que em sistemas compostos 
por diferentes tipos de calcários e diferentes íons metálicos $\left(\mathrm{Pb}^{2+}, \mathrm{Zn}^{2+}, \mathrm{Cd}^{2+} \mathrm{e} \mathrm{Cu}^{2+}\right)$ apresentavam sempre um valor final de $\mathrm{pH}$ de 7,5, sugerindo como causa do $\mathrm{pH}$ final manter-se relativamente constante a capacidade de tamponamento do sistema carbonato. AZIZ, et al. (2008), relataram que o calcário de alta pureza eleva o pH para valores superiores a 8,0 devido à sua capacidade de formar precipitados na forma de hidróxidos ou carbonatos dos metais.

Sabe-se que em soluções diluídas, a formação de produtos da hidrólise de metais pesados ocorre geralmente em $\mathrm{pH}>6 \mathrm{e}$, portanto, a remoção destes metais pesados sob condições alcalinas pode ocorrer também via precipitação provocada pela formação de complexos de íons $\mathrm{Cr}(\mathrm{III})$ e $\mathrm{OH}^{-}$. Além disso, a química de superfície de minerais de carbonato em contato com a água é descrita em termos das reações de coordenação que estes sítios de superfície sofrem com espécies na solução, tais como $\mathrm{Ca}^{2+}, \mathrm{CO}_{3}{ }^{2-}, \mathrm{HCO}_{3}{ }^{-}$e $\mathrm{CaHCO}_{3}{ }^{+}$(SONDI et al., 2009). Para elucidar melhor as possíveis espécies envolvidas na remoção dos íons $\mathrm{Cr}(\mathrm{III})$, foi construído um diagrama de especiação $\log C$ em função do $p H$ monstrado na Figura 2.

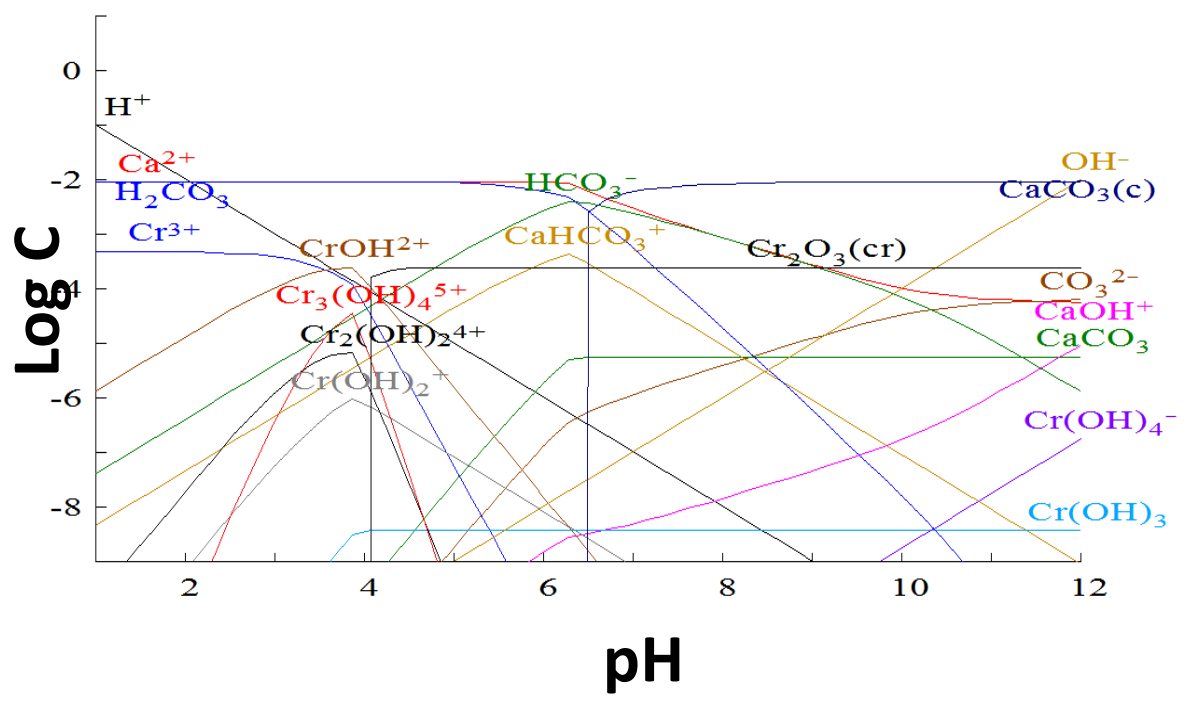

Figura 2: Diagrama de especiação para o sistema $\mathrm{CaCO}_{3}{ }^{2-}$ e $\mathrm{Cr}^{3+}\left(\left[\mathrm{CO}_{3}{ }^{2-}\right]=9,0 \mathrm{mM} ;\left[\mathrm{Ca}^{2+}\right]=9,0 \mathrm{mM}\right.$; e $\left[\mathrm{Cd}^{2+}\right]=0,48$ $\mathrm{mM})$.

Na Figura 2, observa-se que mesmo em meio ácido, vários complexos hidratados solúveis são formados, sugerindo assim, que a maior parcela de $\mathrm{Cr}^{3+}$ solúvel sofre o processo de hidrólise pelas seguintes reações de 1 a 4 :

$$
\begin{gathered}
\mathrm{Cr}(\mathrm{OH})^{2+}+\mathrm{H}^{+} \stackrel{\log \mathrm{K}=-3,56}{\longleftrightarrow} \mathrm{Cr}^{3+}+\mathrm{H}_{2} \mathrm{O} \\
\mathrm{Cr}_{2}(\mathrm{OH})_{2}^{4+}+2 \mathrm{H}^{+} \stackrel{\log \mathrm{K}=-5,06}{\longleftrightarrow} 2 \mathrm{Cr}^{3+}+4 \mathrm{H}_{2} \mathrm{O} \\
\mathrm{Cr}_{3}(\mathrm{OH})_{4}^{5+}+4 \mathrm{H}^{+} \stackrel{\log \mathrm{K}=-8,15}{\longleftrightarrow} 3 \mathrm{Cr}^{3+}+4 \mathrm{H}_{2} \mathrm{O} \\
\mathrm{Cr}(\mathrm{OH})_{2}^{+}+2 \mathrm{H}^{+} \stackrel{\log \mathrm{g}=-9,83}{\longleftrightarrow} \mathrm{Cr}^{3+}+4 \mathrm{H}_{2} \mathrm{O}
\end{gathered}
$$

Segundo POKROVSKY e SCHOTT (2002), em pH mais baixo há uma grande quantidade de íons $\mathrm{H}^{+}$na solução, que podem competir com os íons $\mathrm{Cr}^{3+}$ pelo $\mathrm{CO}_{3}{ }^{2-}$, inibindo a precipitação do metal pelo carbonato sobre a superfície do sorvente. Logo após o processo de hidrólise, praticamente todas as espécies inicialmente formadas sofrem um decréscimo acentuado a partir 
de um $\mathrm{pH}$ de aproximadamente 4, dando origem a formação de dois complexos sólidos que são muito mais estáveis, descritos pelas reações 5 e 6 :

$$
\begin{gathered}
\mathrm{Cr}_{2} \mathrm{O}_{3}+6 \mathrm{H}^{+} \stackrel{\log \mathrm{K}=-15,0}{\longleftrightarrow} 2 \mathrm{Cr}^{3+}+3 \mathrm{H}_{2} \mathrm{O} \\
\mathrm{Cr}(\mathrm{OH})_{3}+3 \mathrm{H}^{+} \stackrel{\log \mathrm{K}=-9,33}{\longleftrightarrow} \mathrm{Cr}^{3+}+3 \mathrm{H}_{2} \mathrm{O}
\end{gathered}
$$

Como pode-se observar na Figura 2, a concentração de $\mathrm{Cr}_{2} \mathrm{O}_{3}$ é significativamente maior que a de $\mathrm{Cr}(\mathrm{OH})_{3}$, isso pode ser devido a diferença das constante de equilíbrio das duas reações, onde a formação de $\mathrm{Cr}_{2} \mathrm{O}_{3}$ é favorecida por apresentar um valor menor de logK. As concentrações destas duas espécies formadas permanecem praticamente constantes a partir deste $\mathrm{pH}$ uma vez que o sistema carbonato tende a neutralizar toda acidez decorrente dos íons $\mathrm{H}^{+}$formados nas reações acima. Este comportamento é descrito por STUMM e MORGAN (1981), em um sistema tamponado por calcita.

Segundo vários autores, os sólidos com composição química a base de $\mathrm{CaCO}_{3}$, podem ser considerados bons sorventes de metais pesados por dois motivos. O primeiro está ligado a superfície deste mineral que é rugosa, resultando em um bom contato entre o sólido e os íons metálicos (CHENG et al., 1998). O segundo é devido a presença dos complexos carbonatados solúveis que causam a precipitação na forma de óxidos e, provavelmente, carbonatos dos metais (AZIZ et al., 2008).

\subsection{Efeito da Concentração Inicial de $\mathrm{Cr}$ (III)}

A Tabela 1 mostra os valores de remoção e captação dos íons $\mathrm{Cr}$ (III) em função das diferentes concentrações iniciais empregadas na faixa de 5 a $400 \mathrm{mg} . \mathrm{L}^{-1}$ no processo de sorção utilizando os $\mathrm{GB}$ a pH 5, concentração de sorvente de $2 \mathrm{~g} . \mathrm{L}^{-1}$, tamanho de partícula: $<38 \mu \mathrm{m}$, temperatura: $25^{\circ} \mathrm{C}$ e tempo de contato: $240 \mathrm{~min}$.

Como pode ser visto na Tabela 1, a medida que a concentração inicial de $\mathrm{Cr}(\mathrm{III})$ é incrementada, a porcentagem de remoção praticamente mantêm-se estável até a concentração de $300 \mathrm{mg} \cdot \mathrm{L}^{-1}$. MA et al. (2012), observou um comportamento semelhante na adsorção dos íons $\mathrm{Pb}^{2+}$ em um material híbrido de $\mathrm{CaCO}_{3}$-maltose. A percentagem de remoção de $\mathrm{Pb}^{2+}$ é quase completa na faixa de concentração inicial de 300 a $900 \mathrm{mg} \cdot \mathrm{L}^{-1}$. Segundo SHAHWAN et al. (2005), a calcita foi capaz de remover os íons $\mathrm{Zn}^{2+}$ quase totalmente (> 99,9\%) em concentrações inferiores a $100 \mathrm{mg} \cdot \mathrm{L}^{-1}$, a partir da concentração de $500 \mathrm{mg} \cdot \mathrm{L}^{-1}$, a remoção decresceu gradativamente até a concentração de $10.000 \mathrm{mg} \cdot \mathrm{L}^{-1}$.

No presente estudo, a partir da concentração de $300 \mathrm{mg} \cdot \mathrm{L}^{-1}$ a remoção diminui gradativamente atingindo os menores valores de remoção, porém, os maiores valores de captação. Os valores máximos de percentagem de remoção dos íons $\mathrm{Cr}(\mathrm{III})$ foram obtidos na faixa menor de concentração inicial. Já as melhores captações foram observadas na concentração inicial de 400 $\mathrm{mg} . \mathrm{L}^{-1}$, correspondendo a $161 \mathrm{mg} \cdot \mathrm{g}^{-1}$, respectivamente. 
Tabela 1: Efeito da concentração inicial de $\mathrm{Cr}(\mathrm{III})$ na sorção por GB.

\begin{tabular}{ccc}
\hline \multirow{2}{*}{$\begin{array}{c}\text { Concentração Inicial } \\
\text { (mg. } \mathbf{L}^{-1} \text { ) }\end{array}$} & \multicolumn{2}{c}{$\mathbf{C r}($ III) } \\
\cline { 2 - 3 } & Remoção (\%) & $\mathbf{q}\left(\mathbf{~ m g . g}^{-1}\right.$ ) \\
\hline 5 & 98,44 & 2,46 \\
20 & 97,97 & 4,90 \\
50 & 98,71 & 12,34 \\
70 & 99,07 & 24,77 \\
100 & 99,42 & 37,28 \\
150 & 99,50 & 49,75 \\
200 & 98,92 & 61,83 \\
250 & 98,98 & 74,24 \\
300 & 98,69 & 98,69 \\
350 & 96,14 & 120,17 \\
400 & 92,05 & 161,09 \\
\hline
\end{tabular}

\subsection{Isotermas de Adsorção}

Mediante a construção das isotermas é possível observar a relação existente entre a quantidade de soluto presente na superfície do sorvente e a quantidade de soluto em equilíbrio com a solução. Os ensaios foram realizados em concentrações iniciais de 5 a $400 \mathrm{mg} . \mathrm{L}^{-1}$ a fim de se obter a capacidade máxima de saturação do GB. A Figura 3 mostram a quantidade de íons $\mathrm{Cr}$ (III) sorvidos (q) em função da concentração destes íons em solução ( $\left.C_{\text {eq }}\right)$.

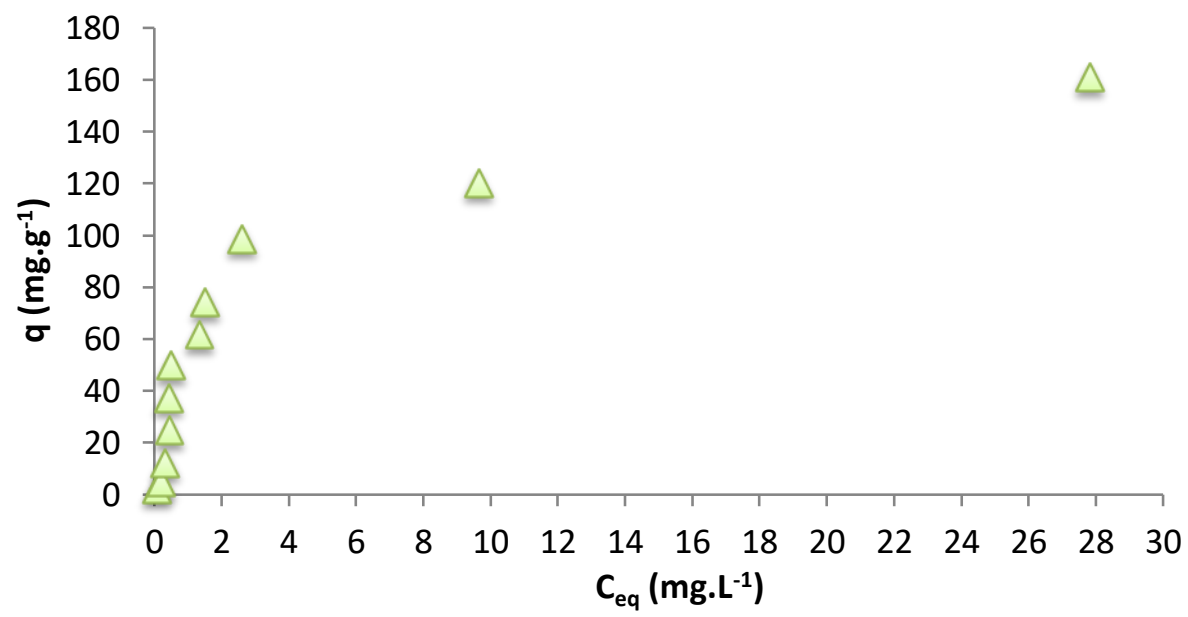

Figura 3: Isoterma de adsorção dos íons $\mathrm{Cr}(\mathrm{III})$ por GB (pH: 5; concentração inicial de sorvente: $2 \mathrm{~g}$. $\mathrm{L}^{-1}$; tamanho de partícula: < $38 \mu \mathrm{m}$; temperatura: $25^{\circ} \mathrm{C}$; e tempo de contato: $240 \mathrm{~min}$ ).

$\mathrm{Na}$ Figura 3 pode-se observar que o perfil da isoterma assemelha-se a do tipo " $\mathrm{S}$ ", ou seja, a sigmoidal. Este tipo de isoterma também conhecida como do tipo Il são em geral, as mais comuns de serem encontradas em medidas de adsorção e ocorrem em sistemas não porosos ou macroporosos (GREGG e SING, 1982). O primeiro segmento da curva, côncavo ao eixo Ceq, representa a formação de uma monocamada adsorvida à superfície do $G B$, enquanto o segundo segmento, convexo ao eixo $C_{\text {eq }}$, representa a adsorção de multicamadas sobre a superfície. Em termos gerais, o ponto de inflexão da isoterma corresponde à ocorrência de completa formação 
da primeira camada e sugere a ocorrência de pelo menos dois mecanismos opostos atuando no processo de sorção dos íons $\mathrm{Cr}$ (III) na superfície dos GB.

Os dados obtidos nos ensaios de equilíbrio apresentados na Figura 3 foram aplicados aos modelos de isoterma de Langmuir, Freundlich, Dubinin-Radushkevich (D-R) e Temkin. As Figuras 4, 5, 6 e 7 correspondem às isotermas de Langmuir, Freundlich, Dubinin-Radushkevich e Temkin, respectivamente. A Tabela 2 mostra os parâmetros obtidos dos modelos de isotermas, as sim como os seus respectivos coeficientes de correlação.

Tabela 2: Constantes de sorção dos íons $\mathrm{Cr}$ (III) em GB.

\begin{tabular}{|c|c|c|c|c|c|c|}
\hline \multirow{2}{*}{ Metal } & \multicolumn{3}{|c|}{ Langmuir } & \multicolumn{3}{|c|}{ Freundlich } \\
\hline & $q_{\max }\left(m g \cdot g^{-1}\right)$ & $\mathrm{K}_{\text {ads }}\left(\mathrm{L} \cdot \mathrm{mg}^{-1}\right)$ & $\mathrm{R}^{2}$ & $\mathrm{~K}_{\mathrm{F}}\left(\mathrm{L}_{\mathrm{m}} \mathrm{mg}^{-1}\right)$ & $\mathrm{n}$ & $\mathrm{R}^{2}$ \\
\hline $\mathrm{Cr}$ (III) & 178,57 & 0,290 & 0,953 & 34,12 & 1,44 & 0,783 \\
\hline \multirow{2}{*}{ Metal } & \multicolumn{3}{|c|}{ Dubinin-Radushkevich } & \multicolumn{3}{|c|}{ Temkin } \\
\hline & $q_{\max }\left(m g \cdot g^{-1}\right)$ & $\beta\left(m g^{2} \cdot \mathrm{kJ}^{-2}\right)$ & $\mathrm{R}^{2}$ & $A\left(L . m g^{-1}\right)$ & $\mathrm{b}\left(\mathrm{kJ} \cdot \mathrm{mol}^{-1}\right)$ & $\mathrm{R}^{2}$ \\
\hline $\mathrm{Cr}$ (III) & 171,19 & 0,672 & 0,942 & 7,75 & 0,08653 & 0,959 \\
\hline
\end{tabular}

Pelos valores obtidos e mostrados na Tabela 2, os dados de sorção de $\mathrm{Cr}$ (III) ajustaram-se melhor aos modelos de Langmuir, Dubinin-Radushkevich e Temkin, apresentando valores de $R^{2}>$ 0,94 . O valor de $q_{\max }$ obtido pelo modelo de isoterma de Langmuir para os íons $\mathrm{Cr}(\mathrm{III})$ foi de 178,57 $\mathrm{mg} \cdot \mathrm{g}^{-1}$. Este valor representa a capacidade máxima de adsorção quando a superfície do GB é totalmente coberta pelos íons $\mathrm{Cr}(\mathrm{III})$. Um valor de $\mathrm{K}_{\mathrm{ads}}$ elevado indica uma alta afinidade entre os íons $\mathrm{Cr}$ (III) e os GB, sendo o valor encontrado de 0,290 L. $\mathrm{mg}^{-1}$.

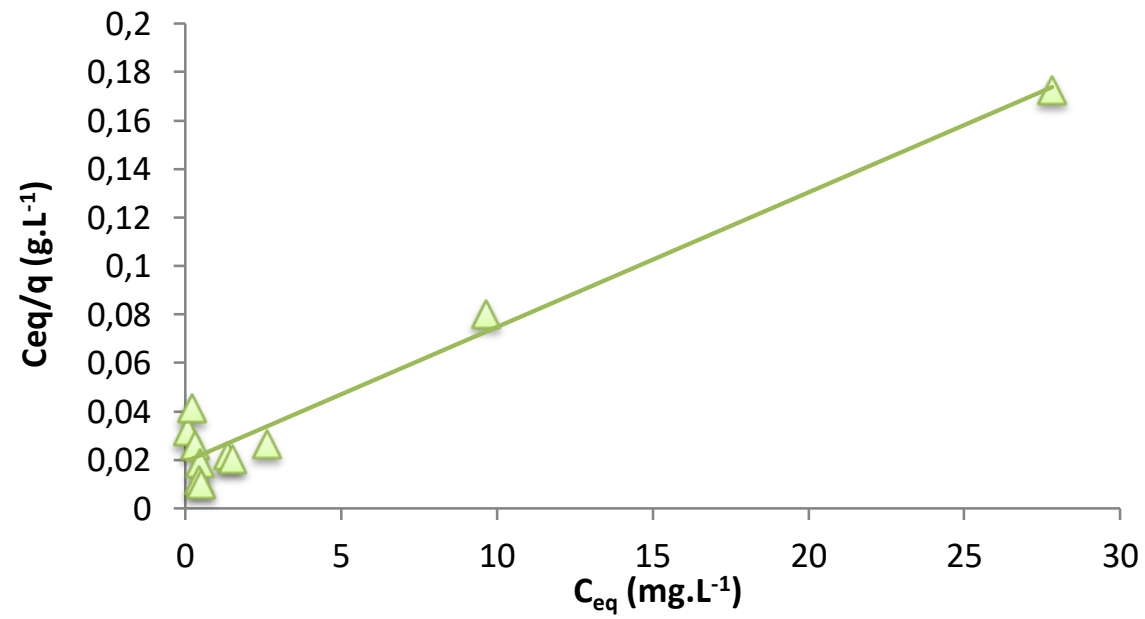

Figura 4: Isoterma de Langmuir linearizada para $\mathrm{Cr}(\mathrm{III})$ em GB (pH: 5; concentração do sorvente: 2 g. $\mathrm{L}^{-1}$; tamanho de partícula: $<38 \mu \mathrm{m}$; temperatura: $25^{\circ} \mathrm{C}$; e tempo de contato: $240 \mathrm{~min}$ ).

Os fatores de separação ou parâmetros de equilíbrio $R_{L}$ calculados a partir dos dados de sorção dos íons $\mathrm{Cr}$ (III) são mostrados na Tabela 3 . Todos os valores de $R_{L}$ obtidos no presente estudo, nas diferentes concentrações iniciais apresentam-se entre 0 e 1 , sugerindo então que a sorção dos íons $\mathrm{Cr}(\mathrm{III})$ nos GB são favoráveis. 
Tabela 3: Valores de $R_{\mathrm{L}}$ para a sorção de $\mathrm{Cr}(\mathrm{III})$ em GB.

\begin{tabular}{cccccccccccc}
\hline & \multicolumn{10}{c}{ Concentração Inicial $\left(\mathrm{mg}^{\mathrm{N}} \mathrm{L}^{-1}\right)$} \\
\cline { 2 - 11 } & 5 & 20 & 50 & 70 & 100 & 150 & 200 & 250 & 300 & 350 & 400 \\
\hline $\mathrm{Cr}(\mathrm{III})$ & 0,41 & 0,15 & 0,06 & 0,05 & 0,03 & 0,02 & 0,02 & 0,01 & 0,01 & 0,01 & 0,01 \\
\hline
\end{tabular}

SDIRI et al. (2011), estudando um argilo mineral enriquecido com carbonato de cálcio observou que os dados de sorção dos íons $\mathrm{Pb}^{2+}, \mathrm{Cd}^{2+}, \mathrm{Cu}^{2+}$ e $\mathrm{Zn}^{2+}$ ajustaram-se bem ao modelo de Langmuir, apresentando valores de $R^{2}$ de 0,$982 ; 0,977 ; 0,989$ e 0,998, respectivamente. Os valores de $q_{\max }, K_{L}$ e $R_{L}$ para os íons $\mathrm{Pb}^{2+}$ foram de $131,6 \mathrm{mg}^{-1} \mathrm{~g}^{-1}, 2,05 \mathrm{~L}_{\mathrm{mg}} \mathrm{mg}^{-1}$ e 0,005 ; para o $\mathrm{Cd}^{2+}$ foram de 6,8 mg.g ${ }^{-1}, 0,12$ L.mg ${ }^{-1}$ e 0,075; para o $\mathrm{Cu}^{2+}$ foram de 27,4 mg.g ${ }^{-1}, 0,19$ L.mg ${ }^{-1}$ e 0,95; e para o $\mathrm{Zn}^{2+}$

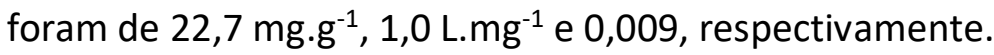

No presente estudo, os dados de sorção dos íons $\mathrm{Cr}(\mathrm{III})$, quando submetidos ao modelo de Freundlich, apresentou o menor valor de $R^{2}$, correspondendo a 0,783. Neste modelo, a constante $K_{F}$ representa uma medida relativa da capacidade de adsorção, e $n$ está relacionado à intensidade de adsorção. Como mostrado, os valores de $K_{F}$ e $n$ para os íons $\mathrm{Cr}(\mathrm{III})$ foram de 34,12 L.mg $^{-1}$ e 1,44, respectivamente. Uma inclinação relativamente leve $n>>1$ indica que a intensidade de sorção é elevada em toda faixa de concentração em estudo, enquanto uma inclinação íngreme ( $n<1$ ) significa que a intensidade de sorção é elevada apenas em altas concentrações, decrescendo em concentrações mais baixas (FRIMMEL e HUBER, 1996). Como pode ser visto, os valores de $n$ são relativamente altos, confirmando os altos valores de sorção nas diferentes concentrações empregadas.

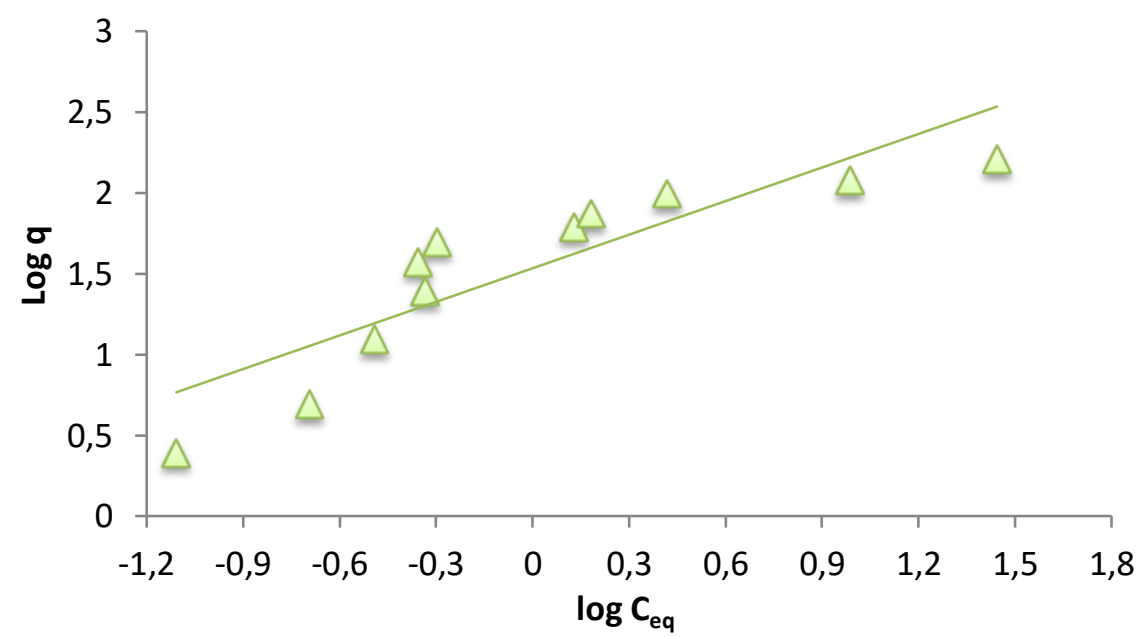

Figura 5: Isoterma de Freundlich linearizada para $\mathrm{Cr}$ (III) em GB (pH: 5; concentração do sorvente: 2 g. $\mathrm{L}^{-1}$; tamanho de partícula: $<38 \mu \mathrm{m}$; temperatura: $25^{\circ} \mathrm{C}$; e tempo de contato: $240 \mathrm{~min}$ ).

Segundo DU et al. (2011), estudando a remoção dos íons $\mathrm{Pb}^{2+}, \mathrm{Cd}^{2+}$ e $\mathrm{Zn}^{2+}$ através do pó de casca de moluscos tanto na fase aragonita como calcita observaram que os dados de sorção para os três metais estudados ajustaram-se bem ao modelo de Freundlich, correspondendo a valores de $\mathrm{R}^{2}>0,986$. Os valores de $n$ obtidos para a aragonita e calcita foram de 7,1 e 8,3 para $\mathrm{Pb}^{2+} ; 16,7$ e 1,6 para $\mathrm{Cd}^{2+}$ e; 7,1 e 6,7 para $\mathrm{Zn}^{2+}$, sugerindo que a sorção é favorável para ambos os metais.

Como já descrito acima, os dados de sorção dos íons $\mathrm{Cr}(\mathrm{III})$ em GB ajustaram-se bem ao modelo de Dubinin-Radushkevich, correspondendo ao valor de $R^{2}$ de 0,942 . Os valores obtidos de 
$q_{\max }$ pelo modelo $\mathrm{D}-\mathrm{R}$ de $171,19 \mathrm{mg}^{-1} \mathrm{~g}^{-1}$ foi bem semelhante ao encontrado pelo modelo de Langmuir. O valor da constante 6 foi de $0,672 \mathrm{mg}^{2} \cdot \mathrm{kJ}^{-2}$. Segundo WANG et al. (2007), a energia livre média de sorção $E_{s}$ pode ser relacionada ao tipo de adsorção, para valores de $E_{s}<8 \mathrm{~kJ} / \mathrm{mol}$, podese dizer que a adsorção é predominantemente de caráter física, ou seja, a sorção de $\mathrm{Cr}$ (III) em GB encontra-se nesta condição, apresentando valor de $0,86 \mathrm{~kJ} . \mathrm{mol}^{-1}$, respectivamente.

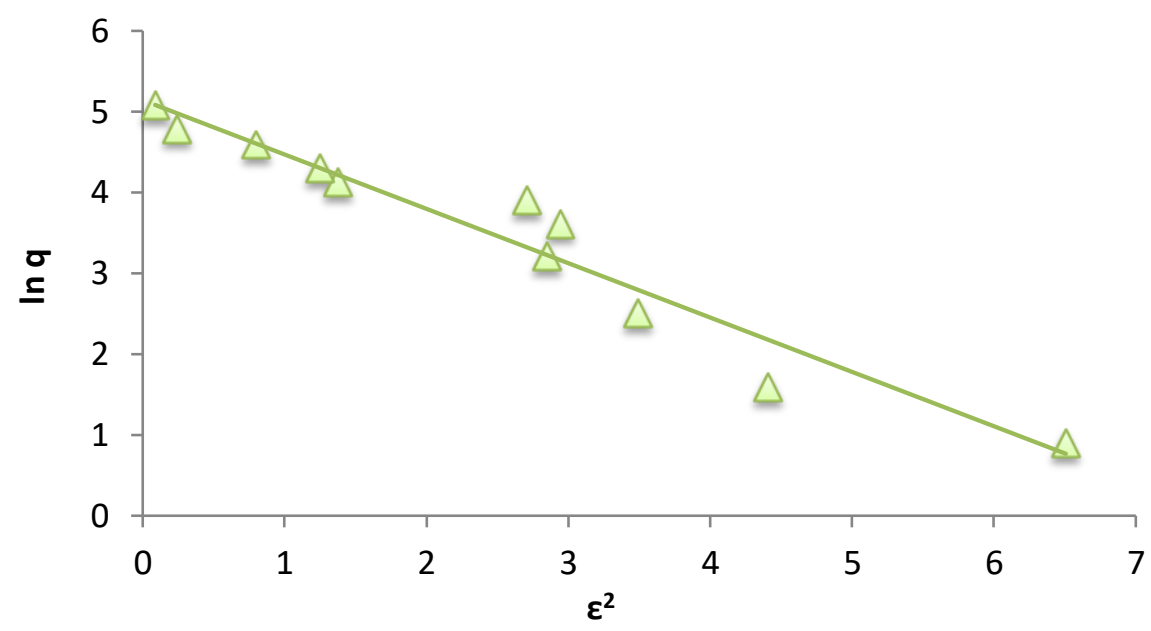

Figura 6: Isoterma de Dubinin-Radushkevich linearizada para $\mathrm{Cr}(\mathrm{III})$ em GB (pH: 5; concentração do sorvente: 2 g.L${ }^{1}$; tamanho de partícula: $<38 \mu \mathrm{m}$; temperatura: $25^{\circ} \mathrm{C}$; e tempo de contato: $240 \mathrm{~min}$ ).

SDIRI et al. (2011), estudando um argilo mineral enriquecido com carbonato de cálcio observou que os dados de sorção dos íons $\mathrm{Pb}^{2+}$ ajustaram-se bem ao modelo de DubininRadushkevich $\left(R^{2}=0,990\right)$, apresentando os valores das constantes $q_{\max }$ e 8 de $149,3 \mathrm{mg} \cdot \mathrm{g}^{-1}, 0,067$ $\mathrm{mol}^{2} \cdot \mathrm{kJ}^{-2}$, respectivamente. Os dados de sorção dos íons $\mathrm{Cr}(\mathrm{III})$ ajustaram-se bem ao modelo de Temkin $\left(R^{2}=0,959\right)$. Os valores das constantes $A$ e $b$ obtidas foram de $7,75 \mathrm{~L} . \mathrm{mg}^{-1}$ e $0,086 \mathrm{~kJ} . \mathrm{mol}^{-1}$. Segundo RANGEL-PORRAS et al. (2010), os dados obtidos nos ensaios de sorção de $\mathrm{Pb}^{2+}$ em um solo rico em calcita (Cal-A) ajustaram-se melhor ao modelo de Temkin do que aos modelos de Langmuir e Freunlinch, apresentando um $R^{2}=0,959$.

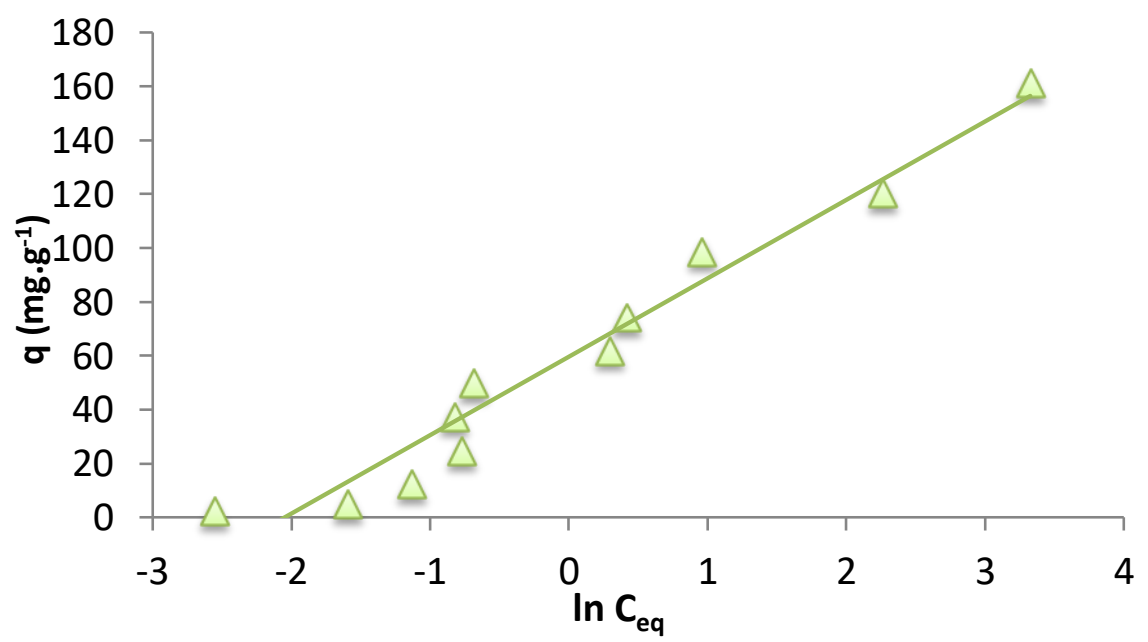

Figura 7: Isoterma de Temkin linearizada para $\mathrm{Cr}$ (III) em GB (pH: 5; concentração do sorvente: 2 g. $\mathrm{L}^{-1}$; tamanho de partícula: < $38 \mu \mathrm{m}$; temperatura: $25^{\circ} \mathrm{C}$; e tempo de contato: $240 \mathrm{~min}$ ).

Este alto coeficiente de regressão para a isoterma de Temkin pode ser devido à dependência linear do calor de sorção em relação a uma camada formada na superfície. Esta 
linearidade pode ser devido a repulsão entre as espécies de adsorvato ligadas aos sítios ativos da calcita ou a heterogeneidade intrínsica da superfície.

\subsection{Microscopia Eletrônica de Varredura}

Na Figura 8A pode-se observar uma partícula de GB antes do processo de sorção. Observase que a superfície é bem irregular, com predominância de cavidades de diferentes tamanhos. Na Figura 8B pode-se notar que as cavidades antes expostas (Figura 8A) aparecem em segundo plano, através de fissuras formadas em uma espécie de camada de precipitados na superfície do GB.

Segundo FORD et al. (2001) existem vários tipos de precipitação incluindo precipitação homogênea, coprecipitação e precipitação induzida de superfície. SPARKS (2005) descreve que a coprecipitação é definida como a precipitação que consiste de espécies químicas derivadas tanto da solução aquosa, quanto da dissolução do mineral. Sugere-se no presente estudo, que o mecanismo predominante no processo de sorção seja a coprecipitação dos íons $\mathrm{Cr}(\mathrm{III})$ na superfície dos $\mathrm{GB}$, compreendendo o crescimento de uma nova fase estrutural sólida amorfa que é formada a partir das espécies $\mathrm{Cr}_{2} \mathrm{O}_{3}$ (reação 5) formadas no seio da solução, que após a dissolução do $\mathrm{CaCO}_{3}$ forma uma nova unidade molecular simples que se repete de forma tridimensional. Um estudo conduzido por SANCHEZ e AYUSO (2002), sobre sorção de metais pesados em calcita concluiu que os íons $\mathrm{Cr}$ (III) foram removidos da solução através da formação de um oxihidrocarbonato de cromo com a seguinte estequiometria $\mathrm{Cr}_{2} \mathrm{O}_{3 x} \mathrm{H}_{2} \mathrm{O}_{y} \mathrm{CO}_{2}$.
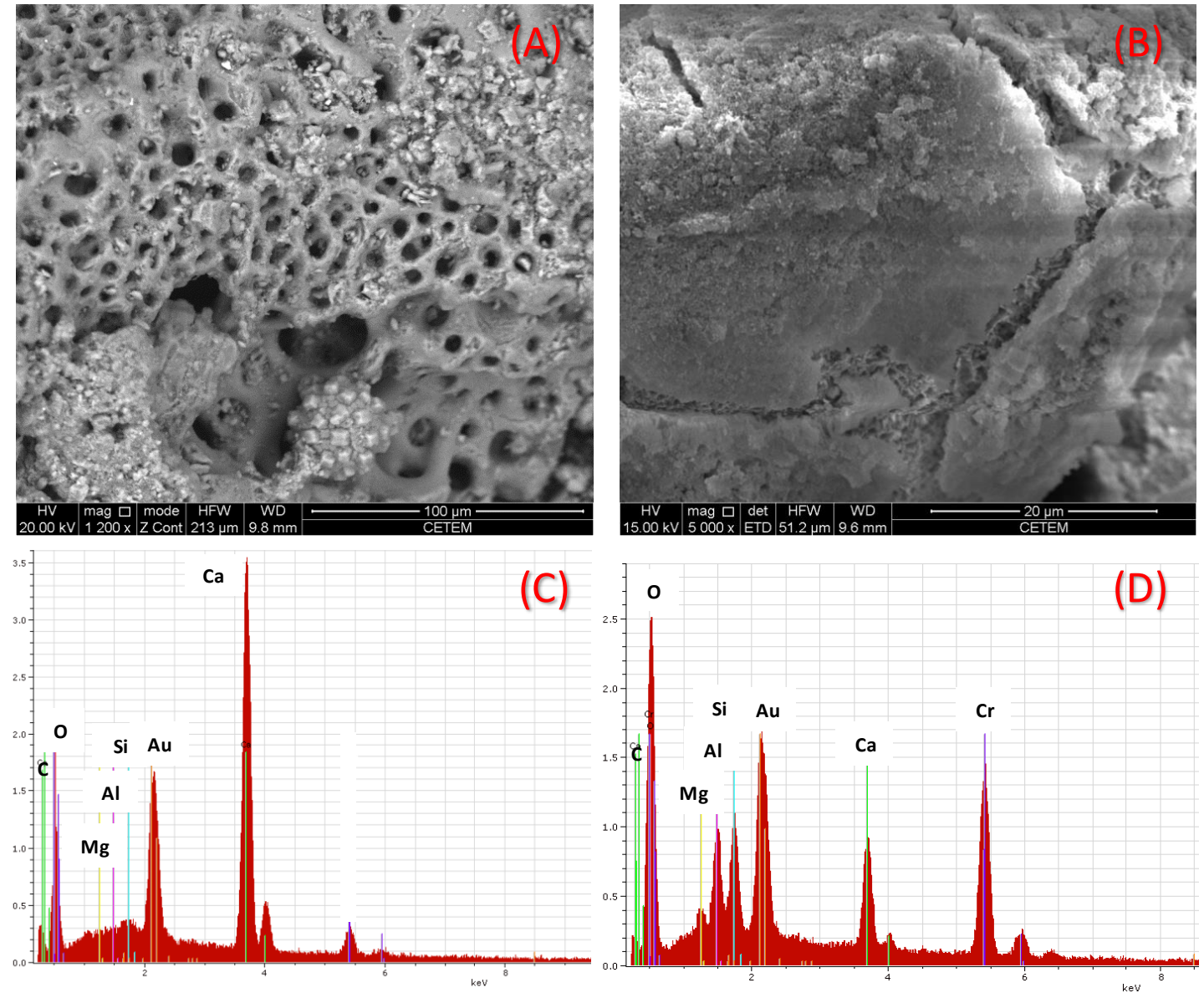

Figura 8: Micrografias/Espectros de partículas de GB antes (A)/(C) e após (B)/(D) do processo de sorção. 
Na Figura 8 C e D pode-se observar os espectros obtidos da superfície de algumas partículas de Granulados Bioclásticos por Energia Dispersiva de Raios-X (EDX) antes e após a sorção com os íons $\mathrm{Cr}(\mathrm{III})$, respectivamente. Pode-se observar que o espectro de $\mathrm{GB}$ antes do processo de sorção (Figura $8 \mathrm{C}$ ) apresenta picos referentes ao elemento $\mathrm{Ca}$, $\mathrm{O}$ e $\mathrm{C}$, característicos de minerais de $\mathrm{CaCO}_{3}$, além de picos dos elementos $\mathrm{Mg}$, $\mathrm{Al}$ e Si. Após o processo de sorção (Figura 8D), os picos de $\mathrm{Al}, \mathrm{Si}$ e $\mathrm{O}$ tiveram um aumento, além do surgimento de um pico expressivo de $\mathrm{Cr}$ e um decréscimo acentuado no pico de Ca.

\section{CONCLUSÃO}

Diante dos resultados obtidos, pode-se concluir que os valores de remoção e captação mais significativos dos íons $\mathrm{Cr}$ (III) foram obtidos na faixa de $\mathrm{pH}$ de 4 a 8, correspondendo a 99,9\% e 12,4 $\mathrm{mg} \cdot \mathrm{g}^{-1}$, respectivamente. Os valores mais representativos de remoção foram obtidos nas concentrações iniciais de 5 a 200 mg. $\mathrm{L}^{-1}$ correspondendo a valores entre 97,97\% e 99,5\%. Para a captação, os valores mais elevados foram obtidos na concentração de $350 \mathrm{mg} . \mathrm{L}^{-1}$, correspondendo a $161 \mathrm{mg} . \mathrm{g}^{-1}$. Os modelos de Langmuir, Dubinin-Radushkevich e Temkin ajustaram-se aos dados de sorção apresentando valores de $R^{2}$ de 0,53; 0,942 e 0,959, respectivamente. Os valores de $q_{\max }$ obtidos do modelo de Langmuir e de Dubinin-Radushkevich foram de $178,57 \mathrm{mg} \cdot \mathrm{g}^{-1}$ e $171,19 \mathrm{mg} \cdot \mathrm{g}$ 1 , respectivamente. As micrografias e os espectros obtidos pelo MEV/EDX mostraram precipitados na superfície das partículas de GB com composições dos elementos $\mathrm{C}$, $\mathrm{O}$ e $\mathrm{Cr}$.

\section{REFERÊNCIAS BIBLIOGRÁFICAS}

1. AZIZ, H.A., ADLAN, M.N., ARIFFIN, K.S. Heavy metals (Cd, Pb, $\mathrm{Zn}, \mathrm{Ni}, \mathrm{Cu}$ and $\mathrm{Cr}(\mathrm{III})$ ) removal from water in Malaysia: post treatment by high quality limestone. Bioresource Technology, v.99, p.1578-1583, 2008.

2. BASHA, S., MURTHY, Z.V.P. Kinetic and equilibrium models for biosorption of $\mathrm{Cr}(\mathrm{VI})$ on chemically modified seaweed Cystoseira indica, Process Biochemistry, v.42, p.1521-1529, 2007.

3. BRASIL. Conselho Nacional do Meio Ambiente - CONAMA. Resolução no 430 de 13 de maio de 2011. Dispõe sobre condições e padrões de lançamento de efluentes, complementa e altera a Resolução no 357, de 17 de março de 2005, do Conselho Nacional do Meio Ambiente CONAMA, 2011.

4. CETESB - Companhia Ambiental do Estado de São Paulo. Crômio e seus compostos - Ficha de Informação Toxicológica. 3p., 2012b. Disponível em: http://www.cetesb.sp.gov.br Acesso em: 04/04/2015

5. CHENG, L., STURCHIO, N.C., WOICIK, J.C., KEMNER, K.M., LYMAN, P.F., BEDZYK, M.J. Highresolution structural study of zinc ion incorporation at the calcite cleavage surface. Surface Science, v.415, p.1976-1982, 1998.

6. DAN'AZUM, S., BICHI, M.H. Industrial pollution and heavy metals profile of Challawa river in Kano, Nigeria, Journal of Applied Sciences in Environmental Sanitation, v.5, p.56-62, 2010.

7. DIAS, C.T.M. Bioclastic Granules: calcareous algae, Brazilian Journal of Geophysics, v.8, p.307318, 2000.

8. $\mathrm{DU}, \mathrm{Y} ., \mathrm{LIAN}, \mathrm{F} ., \mathrm{ZHU}, \mathrm{L}$. Biosorption of divalent $\mathrm{Pb}, \mathrm{Cd}$ and $\mathrm{Zn}$ on aragonite and calcite mollusk 
shells. Environmental Pollution, v.159, p.1763-1768, 2011

9. EL-SHERIF, I.Y., TOLANI, S., OFOSU, K., MOHAMED, O.A., WANEKAYA, A.K. Polymeric nano fibers for the removal of $\mathrm{Cr}$ (III) from tannery waste water. Journal of Environmental Management, v.129, p.410-413, 2013.

10. FEBRIANTO, J., KOSASIH, A.N., SUNARSO, J., JU, Y., INDRASWATI, N., ISMADJI, S. Equilibrium and kinetic studies in adsorption of heavy metals using biosorbent: A summary of recent studies, Journal of Hazardous Materials,v.162, p.616-645, 2009.

11. FOO, K.Y. HAMEED, B.H. Insights into the modeling of adsorption isotherm systems, Chemical Engineering Journal, v.156, p.2-10, 2010.

12. FORD, R.G., SCHEINOST, A.C., SPARKS, D.L. Frontiers in metal sorption/precipitation mechanisms on soil mineral surfaces. Advances in Agronomy, v.74, p.41-62, 2001.

13. FREUNDLICH, H.M.F. Über die adsorption in lösungen. Zeitschrift für Physikalische Chemie, v.57, p.385-470, 1906.

14. FRIMMEL, F.H., HUBER, L. Influence of humic substances on the aquatic sorption of heavy metals on defined minerals phases. Environmental International, v.22, p.507-517, 1996.

15. GADD, G.M. Biosorption: critical review of scientific rationale, environmental importance and significance for pollution treatment, Journal of Chemical Technology and Biotechnology, v.48, p.13-28, 2009.

16. GREGG, S.J., SING, K.S.W. Adsorption, Surface area and Porosity. Academic Press, London, 1982.

17. HO, Y.S., PORTER, J.F., MCKAY, G. Equilibrium isotherm studies for the sorption of divalent metal ions onto peat: copper, nickel and lead single component systems, Water Air Soil Pollution, v.141, p.1-33, 2002.

18. IBRAHIM, M.N.M., NGAH, W.S.W., NORLIYANA, M.S., DAUD, W.R.W., RAFATULLAH, M., SULAIMAN, O., HASHIM, R. A novel agricultural waste adsorbent for the removal of lead (II) ions from aqueous solutions. Journal of Hazardous Materials, v.182, p.377-385, 2010.

19. LANGMUIR, I. The adsorption of gases on plane surfaces of glass, mica, and platinum, Journal of the American Chemical Society, v.40, p.1361-1403, 1918.

20. LEE, R.E. Phycology, $3^{\text {rd }}$ Edition Cambridge : Cambridge University Press, 614 p., 1999.

21. MA, X., LI, L., YANG, L., SU, C., WANG, K., YUAN, S., ZHOU, J. Adsorption of heavy metal ions using hierarchical $\mathrm{CaCO}_{3}$-maltose meso/macroporous hybrid materials: Adsorption isotherms and kinetic studies. Journal of Hazardous Materials, v.209-210, p.467-477, 2012.

22. MOMODU, M.A., ANYAKORA, C.A. Heavy Metal Contamination of Ground Water: The Surulere Case Study. Research Journal Environmental and Earth Sciences, v.2, n.1, p.39-43, 2010.

23. POKROVSKY, O.S., SCHOTT, J. Surface chemistry and dissolution kinetics of divalent metal carbonates. Environmental Science \& Technology, v.36, p.426-432, 2002.

24. RANGEL-PORRAS, G., GARCÍA-MAGNO, J.B., GONZÁLEZ-MUÑOZ, M.P. Lead and cadmium immobilization on calcitic limestone materials. Desalination, v.262, p.1-10, 2010.

25. ROSTAMIAN, R., NAJAFI, M., RAFATI, A.A. Synthesis and characterization of thiolfunctionalized silica nano hollow sphere as a novel adsorbent for removal of poisonous heavy 
metal íons from water: Kinetics, isotherms and error analysis. Chemical Engineering Journal, v.171, p.1004-1011, 2011.

26. SANCHEZ, A.G., AYUSO, E.A. Sorption of $\mathrm{Zn}, \mathrm{Cd}$ and $\mathrm{Cr}$ on calcite: application to purification of industrial wastewater. Minerals Engineering, v.15, p.539-547, 2002.

27. SDIRI, A., HIGASHI, T., JAMOUSSI, F., BOUAZIZ, S. Effects of impurities on the removal of heavy metals by natural limestones in aqueous systems. Journal of Environmental Management, v.93, p.245-253, 2012.

28. SDIRI, A., HIGASHIA, T., HATTAB, T., JAMOUSSIC, F., TASE, N. Evaluating the adsorptive capacity of montmorillonitic and calcareous clays on the removal of several heavy metals in aqueous systems. Chemical Engineering Journal, v.172, p.37-46, 2011.

29. SELATINIA, A., BAKHTI, M.Z., MADANI, A., KERTOUS, L., MANSOURI, Y. Biosorption de Cd ${ }^{2+}$ from aqueous solution by a $\mathrm{NAOH}$ treated bacterial dead Streptomyces rimosus biomass. Hydrometallurgy, v.75, p.11-24, 2004.

30. SHAHWAN, T., ZÜNBÜL, B., TUNUSOĞLU, Ö., EROĞLU, A.E. AAS, XRPD, SEM/EDS, and FTIR characterization of $\mathrm{Zn}^{2+}$ retention by calcite, calcite-kaolinite, and calcite-clinoptilolite minerals. Journal of Colloid and Interface Science, v.286, p.471-478, 2005.

31. SONDI, I., BISCAN, J., VDOVIC, N., SKAPIN, S.D. The electrokinetic properties of carbonates in aqueous media revisited. Colloids and Surfaces A: Physicochemical and Engineering Aspects, v.342, p.84-91, 2009.

32. SPARKS, D.L., Sorption | Metals. In: HILLEL, D., HATFIELD , J.L., POWLSON, D.S., ROSENWEIG, C., SCOW, K.M., SINGER, M.J., SPARKS, D.L. Encyclopedia of Soils in the Environment, Oxford UK: Ed. Elsevier Ltd, p.532-537, 2005.

33. STUMM, W., MORGAN, J.J. Aquatic Chemistry: An Introduction Emphasizing Chemical Equilibria in Natural Waters. $2^{\text {nd }}$ Ed., JoHn Wiley \& Sons, 1981.

34. SUWALSKY, M., CASTRO, R., VILLENA, F., SOTOMAYOR, C.P. Cr(III) exerts stronger structural effects than $\mathrm{Cr}(\mathrm{VI})$ on the human erythrocyte membrane and molecular models. Journal of Inorganic Biochemistry, v.102, p.842-849, 2008.

35. TOREM, M.L., CASQUEIRA, R. Flotação Aplicada à Remoção de Metais Pesados. Série Tecnologia Ambiental, v.28: CETEM. Rio de Janeiro, 2003.

36. WANG, J., CHEN, C. Biosorption of heavy metals by Saccharomyces cerevisiae: a review. Biotechnology Advances, v.24, p.427-451, 2006.

37. WANG, X., HUANG, J., HUAI, Q., WANG, J., QIN, Y. Determination of kinetic and equilibrium parameters of the batch adsorption of $\mathrm{Ni}(\mathrm{II})$ from aqueous solutions by Na-Mordenite, Journal of Hazardous Materials, v.142, p.468-476, 2007.

38. ZOUBOULIS, A.I., LOUKIDOU, M.X., MATIS, K.A. Biosorption of toxic metals from aqueous solutions by bacteria strains isolated from metal-polluted soils. Process Biochemistry, v.39, p.909-916, 2004. 